\title{
Meta-Analysis
}

\section{Compliance with iron and folic acid supplementation and associated factors among pregnant women in Ethiopia: a systematic review and meta-analysis}

\author{
Meseret B. Fite ${ }^{1 *}$, Addisalem D. Denio ${ }^{2}$, Ahmed Muyhe², Elias Merdassa ${ }^{1}$, \\ Markos Desalegn ${ }^{1}$, Temesgen T. Gurmesa ${ }^{3}$
}

\begin{abstract}
${ }^{1}$ Department of Public health, Health Science Institute, Wolega University, Ethiopia
${ }^{2}$ Department Public health, College of Medicine and Health Sciences, Dire Dawa University, Ethiopia

${ }^{3}$ Malaria and NTD directorate, Armauer Hansen Research Institute, Ministry of Health, Addis Ababa, Ethiopia
\end{abstract}

Received: 23 August 2020

Revised: 02 October 2020

Accepted: 05 October 2020

\section{*Correspondence:}

Dr. Meseret Belete Fite,

E-mail: meseretphd2014@gmail.com

Copyright: () the author(s), publisher and licensee Medip Academy. This is an open-access article distributed under the terms of the Creative Commons Attribution Non-Commercial License, which permits unrestricted non-commercial use, distribution, and reproduction in any medium, provided the original work is properly cited.

\section{ABSTRACT}

Background: Anaemia is one of the world's leading cause of disability and the most serious global health issues. Globally about 38\% (32 million) pregnant women are anaemic, from which 46.3\% (9.2 million) are in Africa.

Methods: Works of articles from PubMed, Medline and Google Scholar journal data-base were considered. Entirely articles allied to compliance and determinants of AFA supplementation were captured. The authors used modified Newcastle-Ottawa quality appraisal rule for cross-sectional works to assess the excellence of the studies for consideration and, tracked preferred reporting items for systematic reviews and meta-analysis guideline. The pooled effect size was calculated with the review manager and compressive meta-analysis software.

Results: Eighteen studies with a total of 6649 pregnant women were included for analysis. Compliance of IFA supplementation in pregnancy in Ethiopia was 46.1\%. Women who had experienced counselling on IFAS were 1.16 times, OR:1.16, (95\% CI, 0.54, 2.50), knowledge on IFAS were 3.20 times, OR:3.20, (95\% CI, 1.31, 7.85), knowledge of anaemia were five times OR:5.10, (95\% CI, 1.87, 13.94), fourth visit for ANC were 1.58 times OR:1.58, (95\% CI, 0.59, 3.42) and early registration for ANC were three times OR: 3.19, (95\% CI, 0.77, 13.26) more likely to have compliance with IFAS compared to their counterpart.

Conclusions: There is low compliance of IFAS in different parts of Ethiopia. Lack of counselling on IFAS, knowledge of IFAS and anaemia, no fourth visit for ANC and timing in ANC registration were factors that hinder compliance of IFAS.

Keywords: Compliance, Anaemia, IFAS, Ethiopia

\section{INTRODUCTION}

Anaemia is one of the world's leading cause of disability and the most serious global public health issues. Worldwide almost $38 \%$ (32 million) women in pregnancy are anaemic, from which $46.3 \%$ (9.2 million) are in Africa. ${ }^{1}$ Though the causes are often vary; anaemia in pregnancy is extremely prevalent in global both industrialized and unindustrialized countries. ${ }^{2}$ There is considerable variation of prevalence anaemia in pregnancy within developed countries, in which the rate is $18 \%$ in USA, $20 \%$ in Australia, $67.8 \%$ in Singapore and $70 \%$ in China, whereas, the rates increase across trimesters. $^{3-5}$ However, the prevalence is increasing in developing countries, with rate of $50.1 \%$ in Ethiopia, $53 \%$ in Sudan, $71 \%$ in Guinea and $76.7 \%$ in Pakistan that is why anaemia has got consideration as public health concerns. ${ }^{6-8}$ 
Anaemia in pregnancy has been connected to adverse pregnancy outcome and foetal development. ${ }^{9}$ These sound effects comprise; premature birth, LBW, abortion, delay psychomotor improvement and impairment of children's cognitive performance, and lesser totals on intelligence (IQ) test. ${ }^{10}$ Moreover, the effects of iron deficiency anaemia (IDA) in early stages of child and early childhood are not possibly to be adjusted by consequent iron treatment. ${ }^{11}$ Iron consumption increase maternal mean haemoglobin concentration by 4.59 to $5.46 \mathrm{~g} / \mathrm{L}$. Hence, excessive consumption of iron at first or subsequent trimester pregnancy is meaningfully associated with decreased the threat of anaemia and, then lessens adverse birth outcome; premature birth and LBW. ${ }^{6}$ Likewise, women in Sub-Saharan Africa consume low iron, calcium and folic having food assembly which is less than RDA (recommended dietary allowances) requirements in pregnancy for the reason that they were economically not established. ${ }^{12}$

A plenty of works had examined multiple aspects upsetting anaemia in pregnancy. Therefore, maternal age, residence, literateness, antenatal care visit, interpregnancy interval, iron food consumption, dietary practice, micronutrient intake, dietary diversity, iron supplementation, parasite infection and gravidity were documented as factors related with anaemia in pregnancy. ${ }^{13}$ Besides, women of third trimester pregnancy are more likely risky to develop anaemia as compared to first and second trimester. ${ }^{11}$ To lessen burden of anaemia, WHO suggests day-to-day supplementation by 30-60 $\mathrm{mg} / \mathrm{d}$ elemental iron $+400 \mu \mathrm{g}$ folic acid. ${ }^{1}$ Conversely, adherence to iron and folic-acid supplementation (IFAS) in Sub-Saharan Africa has to some extent better; quiet leftovers at substandard level in which adherence proportion ranges from $10.6 \%$ in Kenya to $79 \%$ in Mozambique. $^{12}$

Several published articles on compliance with iron and folic-acid supplementation (IFAS) in pregnancy in Ethiopia are documented. ${ }^{14-31}$ Nevertheless there is no systematic review and meta-analysis conducted on prevalence and determinants of IFA supplementation. Empirically the current overall prevalence of IFAS in pregnancy is not identified in this setup. Therefore, the problem could be undetectable to policy makers. Thus, in order to sum up studies conducted in different corners of country and give overall prevalence and determinants of compliance with IFAS in Ethiopia.

\section{METHODS}

Literature of articles from pubmed, medline and google scholar journal data base was retrieved. To raise the allinclusiveness of the study findings, uniterms and bole operators in English were used in searching strategies. The search terms used were; compliance of iron and folic acid supplementation or compliance of iron and folic acid supplementation during pregnancy or determinants of compliance of iron and folic acid supplementation and Ethiopia were used.

\section{Literature search}

All articles related to compliance of iron and folic acids supplementation were retrieved. Since year of publication were not limited, all artless published to February 25, 2020 were accessed for eligibility in the review. Studies of cross-sectional quantitative study design were included. Nevertheless, articles published in qualitative methods were excluded. All authors accessed the title and abstract independently. To avoid biases, all eligible articles were screened and selected after full abstract the paper were reviewed individually. Finally divergence was managed based on pre-set inclusion criteria.

\section{Data extraction and quality assessment}

All authors involved were involved in data extraction. Data exaction template which include name of authors, publication years, study area, sample size, odds ratio, confidence intervals and $\mathrm{p}$ value, counselling on IFAS, knowledge of IFA supplementation, knowledge of anaemia, fourth visit for ANC and early registration for ANC were prepared before data extraction was performed. After all researchers extracted data independently. Results were cross checked and compared. All researchers discussed and came to consensus to if disparity was upraised.

In current study modified Newcastle-Ottawa scale (MNOS) quality appraisal rule was used for crosssectional works to assess the excellence of the studies for consideration and, tracked preferred reporting items for systematic reviews and meta-analyses (PRISMA) guideline. The over-all mark for the MNOS for cross sectional works was nine stars as a highest for the total scale with the lowest of zero. Articles were considered as high excellence in condition if attained 7 out of 9, average if it attained 5 out of 9 and low if it attained below 5 out of $9 .{ }^{33}$

\section{Outcome interests}

Prevalence of compliance with IFAS in pregnancy was the key outcome of this work. WHO defined antenatal care visit is care provided by skilled health personnel (doctor, nurse or midwife) during pregnancy. Trimester is the number of weeks during pregnancy (first, 1-12 weeks, second, 13-26 weeks, and third, 27-40 weeks). Good adherence was considered as a pregnant woman who took $\geq 65 \%$ of the total prescribed IFA supplementation per month; whereas the opposite is true for non-adherence.

\section{Statistically analysis}

Extracted data prepared in Microsoft excel were exported to review manager software version 5.3 and compressive meta-analysis version 2 for analysis. Statistical 
description related to compliance and determinants With IFAS was performed. We tested publication bias by funnel plot and additionally empirically by Egger's regression test and the degree of reliability was evaluated to assess the occurrence of statistical heterogeneity. Heterogeneity of studies was measured with the I-squared statistic, in which 25,50 , and $75 \%$ characterized low, moderate and high heterogeneity correspondingly. Subgroup analysis was done by the study sub-region and study type (community based or/and facility based). The influence of selected predictor's variables which include: intestinal parasite infection, IFA supplementation, third trimester pregnancy and dietary diversity score (DDS) was analyzed by isolated sets of meta-analysis. The results of the meta-analysis were displayed in forest pilot and odd ratio (OR) with $95 \%$ confidence interval (CI).

\section{RESULTS}

\section{Literature search}

In the beginning, we identified studies related to prevalence of compliance and determinants of IFA supplementation for inclusion in meta-analysis. Accordingly, we found complete of 135 published studies. From these, 110 were banned for the reason inclusion criterion was not contented. An overall 25 full text of studies were cleaned and carefully chosen for eligibility. Out of these 7 studies were removed due to poor statistical reports and deficient data occur. Lastly, 18 studies were added in analysis (Figure 1).

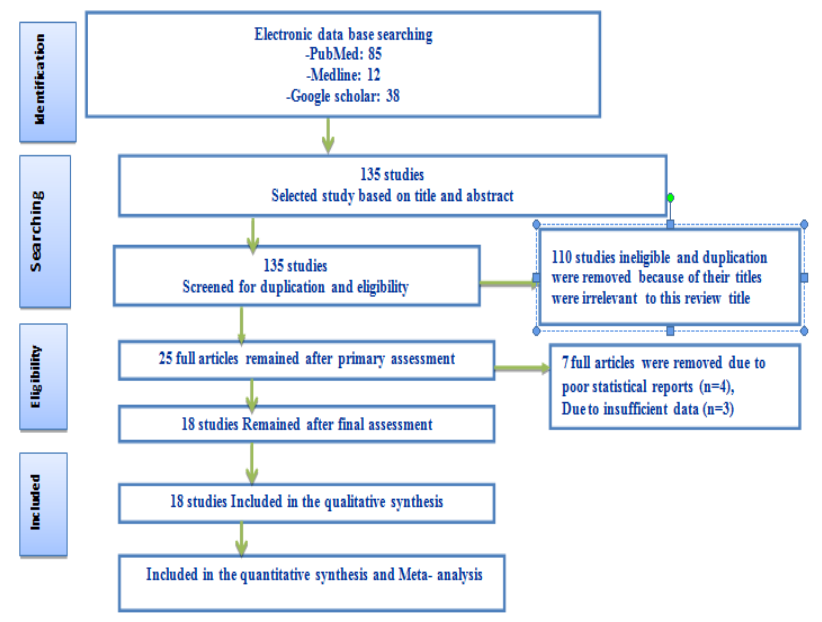

Figure 1: Flow diagram of the studies included in the meta-analysis.

\section{Characteristics of included studies}

Twenty five cross-sectional articles were involved in the meta-analysis (Table 1). ${ }^{14-31}$

Table 1: Summary characteristics of included studies in meta-analysis.

\begin{tabular}{|c|c|c|c|c|c|}
\hline Study authors & $\begin{array}{l}\text { Year of } \\
\text { publication }\end{array}$ & $\begin{array}{l}\text { Regional location in } \\
\text { Ethiopia }\end{array}$ & $\begin{array}{l}\text { Sample } \\
\text { size }\end{array}$ & $\begin{array}{l}\text { Prevalence of } \\
\text { anaemia in } \%\end{array}$ & $\begin{array}{l}\text { Score of modified } \\
\text { Newcastle-Ottawa } \\
\text { scale }\end{array}$ \\
\hline Sadore et al ${ }^{14}$ & 2015 & SNNP & 296 & 39.2 & 7 \\
\hline Taye et al ${ }^{15}$ & 2015 & Amhra & 628 & 20.4 & 8 \\
\hline Demis et al & 2019 & SNNP & 422 & 43.1 & 7 \\
\hline Gashaaw et al & 2018 & Amhra & 418 & 28.7 & 8 \\
\hline Gebreamlak et al & 2017 & Addis Aba & 557 & 60 & 7 \\
\hline Gebremariam et al & 2019 & Amhra & 241 & 40 & 6 \\
\hline Gebremedhin et al & 2014 & National & 553 & 74.9 & 6 \\
\hline Gebremichael et al & 2019 & Tigray & 200 & 10.5 & 7 \\
\hline Getachew et al & 2018 & Tigray & 320 & 64.7 & 8 \\
\hline Dessie & 2018 & Amhra & 348 & 19 & 6 \\
\hline Abdi et al & 2018 & Dire Dawa & 217 & 76 & 5 \\
\hline Jikamo et al & 2018 & SNNP & 365 & 69.59 & 8 \\
\hline Kassa et al & 2019 & SNNP & 402 & 38.3 & 7 \\
\hline Molla et al & 2019 & Amhra & 348 & 52.9 & 6 \\
\hline Boti et al & 2018 & SNNP & 317 & 51.4 & 5 \\
\hline Niguse and Murugan & 2018 & Oromia & 296 & 59.8 & 6 \\
\hline Shewasinad et al & 2017 & SNNP & 326 & 70.6 & 7 \\
\hline Tarekegn et al & 2019 & Amhra & 395 & 28.0 & 8 \\
\hline
\end{tabular}

Out of these six studies $(33.3 \%)$, were conducted in Amhara, six (33.3\%) in Southern Nation Nationality and peoples of Ethiopia (SNNP), one $(5.5 \%)$ in Oromia, two $(11 \%)$ in Tigray, one $(5.5 \%)$ in Dire Dawa city administration, one (5.5\%) in Addis Ababa city administration and one $(5.5 \%)$ national study. The highest sample size was from Amhara with sample size of 628 and the minimum was from Tigray with sample size of 200 and the mean age of the respondent was 27 years. ${ }^{17,21}$ Out of eighteen included studies; fourteen of 
the studies were facility based and the rest four were community based. ${ }^{16-18,21-25,27-31,33}$

\section{Prevalence of compliance toward iron and folic-acid supplementation}

The minimum prevalence of compliance $10.5 \%$ was observed from study conducted in Tigray. ${ }^{21}$ The highest (74.9\%) was observed in study conducted at National level. ${ }^{20}$ The pooled prevalence of compliance with Iron and folic-acid supplementation (IFAS) among pregnant women in Ethiopia was $46.1 \%$ (95\% CI, 0.388-0.558). The heterogeneity test revealed $\mathrm{I}^{2}=98.14 \%$ and statistical evidence of heterogeneity, $\mathrm{p} \leq 0.00001)$. Therefore, random-effect analysis was used. The Bag's and Egger's test for publication bias also showed, no statistical evidence of publication bias, $\mathrm{p}=0.704$ and $\mathrm{p}=0.459$ respectively (Figure 2).

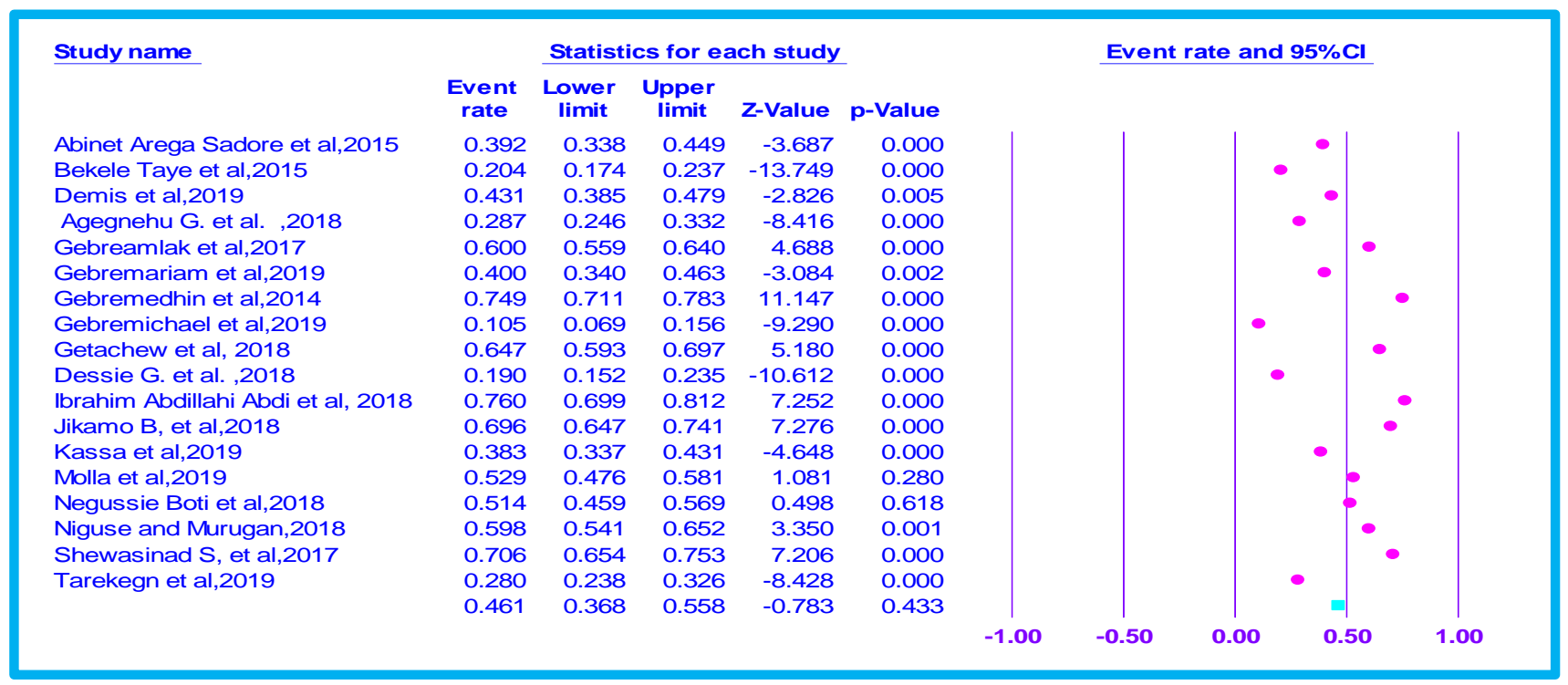

Figure 2: Forest plot displaying the pooled prevalence of compliance with IFAS in pregnancy in Ethiopia.

Table 2: Subgroup analysis of prevalence of compliance with iron and folic acid among pregnant women in Ethiopia.

\begin{tabular}{|c|c|c|c|c|c|c|}
\hline Sub group & $\begin{array}{l}\text { No. } \\
\text { included in } \\
\text { studies }\end{array}$ & $\begin{array}{c}\text { Prevalence } \\
(95 \% \text { CI) }\end{array}$ & $\begin{array}{l}\text { Heterogeneity } \\
\text { statistics }\end{array}$ & $\begin{array}{l}\text { Tau } \\
\text { squared }\end{array}$ & p value & $\mathbf{I}^{2}$ \\
\hline \multicolumn{7}{|l|}{ By region } \\
\hline Addis Ababa & 1 & $60(0.559,0.64)$ & - & - & - & - \\
\hline Amhara & 6 & $30.5(0.213,0.415)$ & 139.04 & 0.349 & $<0.000$ & 96.403 \\
\hline Dire Dawa & 1 & $76(0.699,0.812)$ & - & - & - & - \\
\hline National & 1 & $74.9(0.711,0.783)$ & - & - & - & - \\
\hline Oromia & 1 & $59.8(0.541,0.652)$ & - & - & - & - \\
\hline SNNP & 6 & $52.3(0.404,0.639)$ & 147.25 & 0.348 & $<0.000$ & 96.624 \\
\hline Tigiray & 2 & $31.8(0.031,0.874)$ & 112.958 & 3.3444 & $<0.000$ & 99.115 \\
\hline \multicolumn{7}{|l|}{ By study type } \\
\hline Facility based & 14 & $47.2(0.372,0.574)$ & 577.334 & 0.597 & & 97.797 \\
\hline Community based & 4 & $42.7(0.206,0.681)$ & 320.783 & 1.148 & & 99.065 \\
\hline
\end{tabular}

\section{Subgroup analysis}

We performed a subgroup analysis by classifying studies into corresponding regional location in Sub-Saharan Africa in order to calculate and relate the prevalence of compliance of IFA supplementation athwart various participants' characteristics. Grounded on this analysis, the lowest magnitude of compliance of IFA supplementation in pregnancy was documented In Tigiray region 31.8 (CI: $0.031,0.874$ ) and the highest was in Dire Dawa city administration 76 (CI: 0.699, 0.812). A higher magnitude $(44.3 \%)$ of compliance with IFAS in pregnancy was documented studies investigated at facility level than community based studies 47.2 (CI: $0.372,0.574$ ) (Table 2). 


\section{Counselling on iron and folic acid supplementation}

Out of eighteen studies included in meta-analysis; seven of them documented as counselling on IFA supplementation was associated with compliance of IFAS supplementation in pregnancy. ${ }^{14,16,18,19,22,25,31}$ Likewise, the result of meta-analysis showed, women who had experiences of counselling on IFA supplementation infections in their course of pregnancy were 31.16 times

more likely to adhere compared to those with no experience of counselling during pregnancy, OR:1.16 (95\% CI $0.54,2.50)$. We performed heterogeneity test and the $\mathrm{I}^{2}=94 \%$ and statistical indication of heterogeneity, $\mathrm{p} \leq 0.00001)$. Therefore, random-effect analysis was second hand. The Bag's and Egger's test for publication bias also exhibited, no statistical indication of publication bias, $\mathrm{p}>0.05$ and $\mathrm{p}=0.953$ correspondingly (Figure 3 ).

\section{Knowledge of iron folic acid supplementation}

Association of lack of knowledge of iron folic-acid supplementation and risk of developing noncompliance to IFAS during pregnancy was reported in seven studies. ${ }^{14,15,19,23,26-28}$ The result of meta-analysis showed that, pregnant women who had knowledge on supplementation of IFAS were 3.20 times more likely to have compliance of IFAS during pregnancy compared to those with women who had no knowledge of IFAS, OR: 3.20 , (95\% CI, 1.31, 7.85). The heterogeneity test showed $\mathrm{I}^{2}=96 \%$ and statistical evidence of heterogeneity, $\mathrm{p} \leq 0.0000)$. Therefore, random-effect analysis was used. The Bag's and Egger's test for publication bias also showed, no statistical evidence of publication bias, $p=$ 0.710 and $p=0.918$ respectively (Figure 4 ).

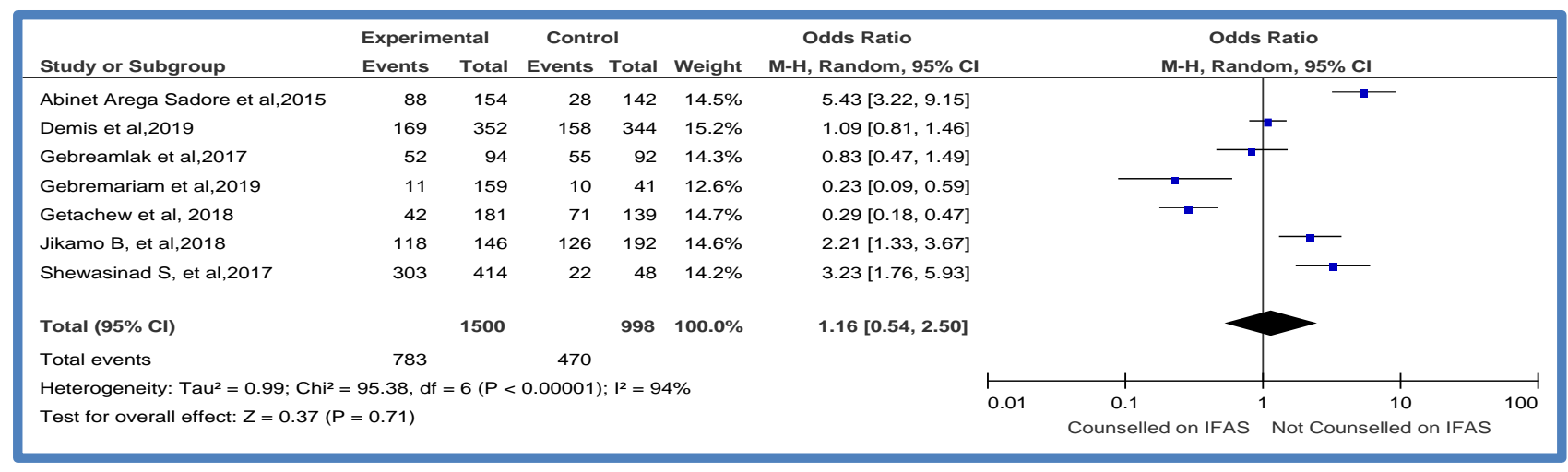

Figure 3: Forest plot displaying association of counseling on Iron and folic acid supplementation with compliance with IFAS among pregnant women in Ethiopia.

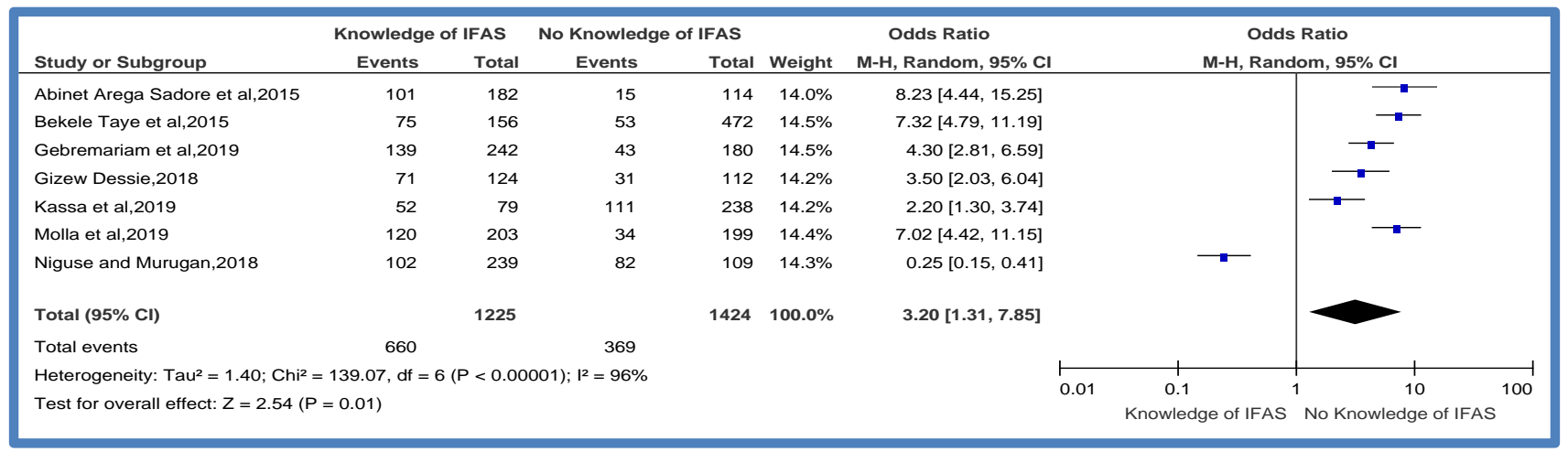

Figure 4: Forest plot displaying association of Knowledge of iron folic acid supplementation with compliance with IFAS among pregnant women in Ethiopia.

\section{Knowledge of anaemia during pregnancy}

Association of lack of knowledge iron folic-acid supplementation and risk of developing noncompliance to IAFAS during pregnancy was reported in eight studies. ${ }^{14-}$ $16,22,25,27,31$ The result of meta-analysis showed that, pregnant women who had knowledge of anaemia during pregnancy were 5.42 times more likely to have compliance of IFAS during pregnancy compared to those women who had no knowledge of anaemia, OR: 5.42, (95\% CI, 1.51, 13.43).The heterogeneity test showed $\mathrm{I}^{2}=97 \%$ and statistical evidence of heterogeneity, $\mathrm{p} \leq 0.0000)$. Therefore, random-effect analysis was used. The Bag's and Egger's test for publication bias also showed, no statistical evidence of publication bias, $\mathrm{p}=0.907$ and $\mathrm{p}=0.371$ respectively (Figure 5). 


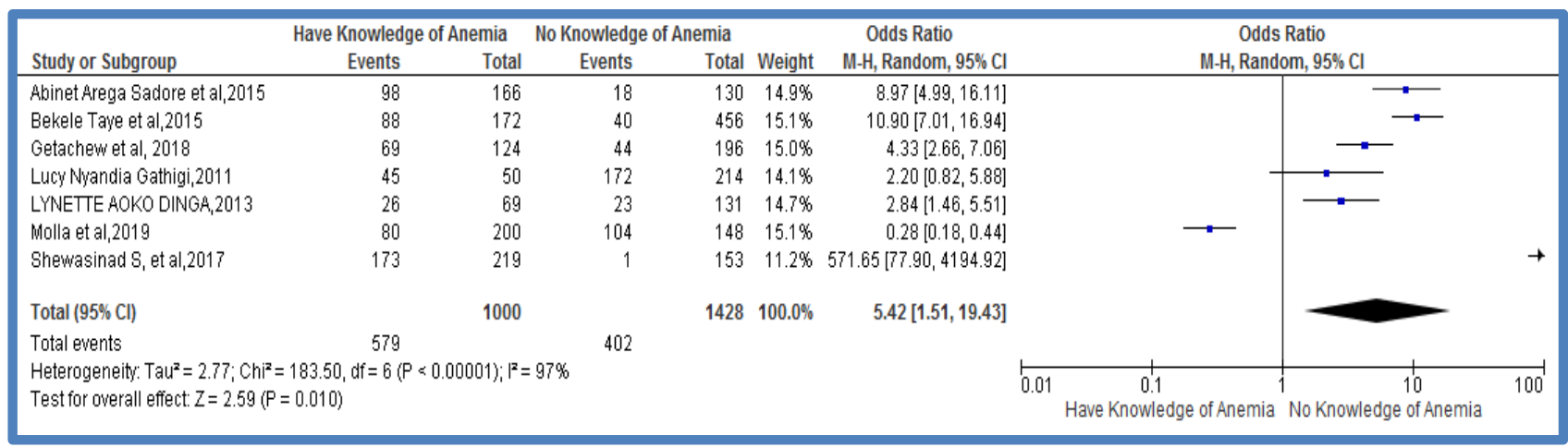

Figure 5: Forest plot displaying association of knowledge of anaemia during with compliance with IFAS among pregnant women in Ethiopia.

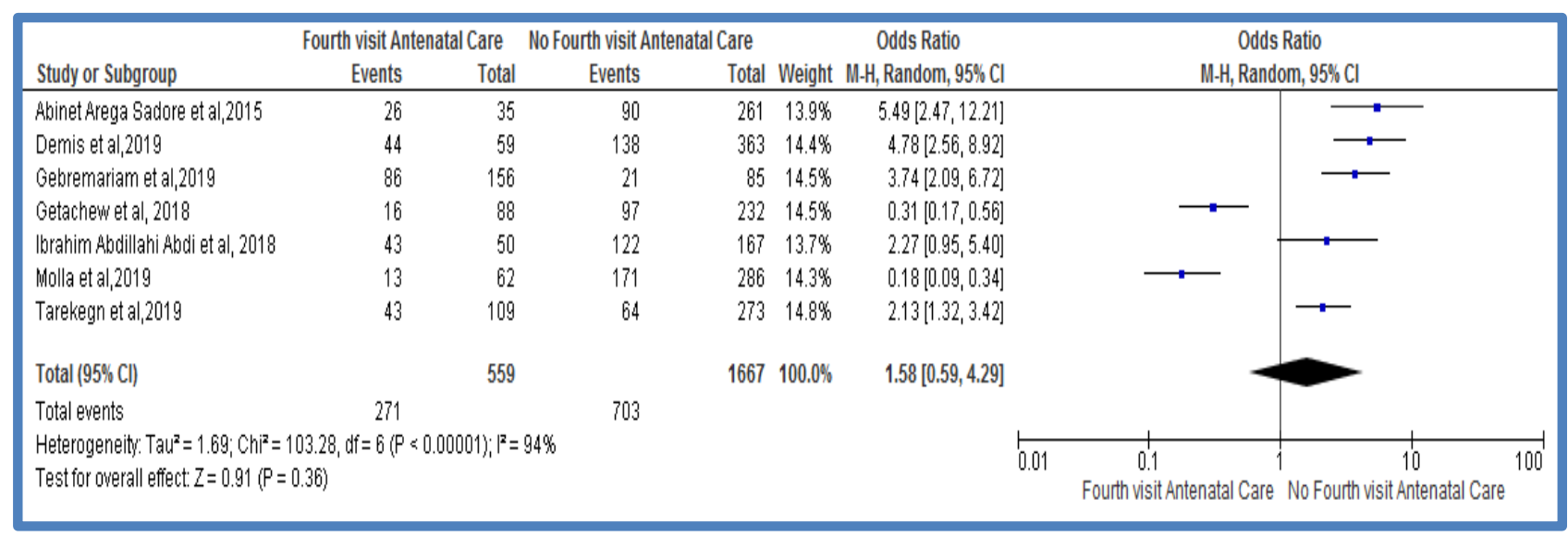

Figure 6: Forest plot displaying association of fourth visit for antenatal care with compliance with IFAS among pregnant women in Ethiopia.

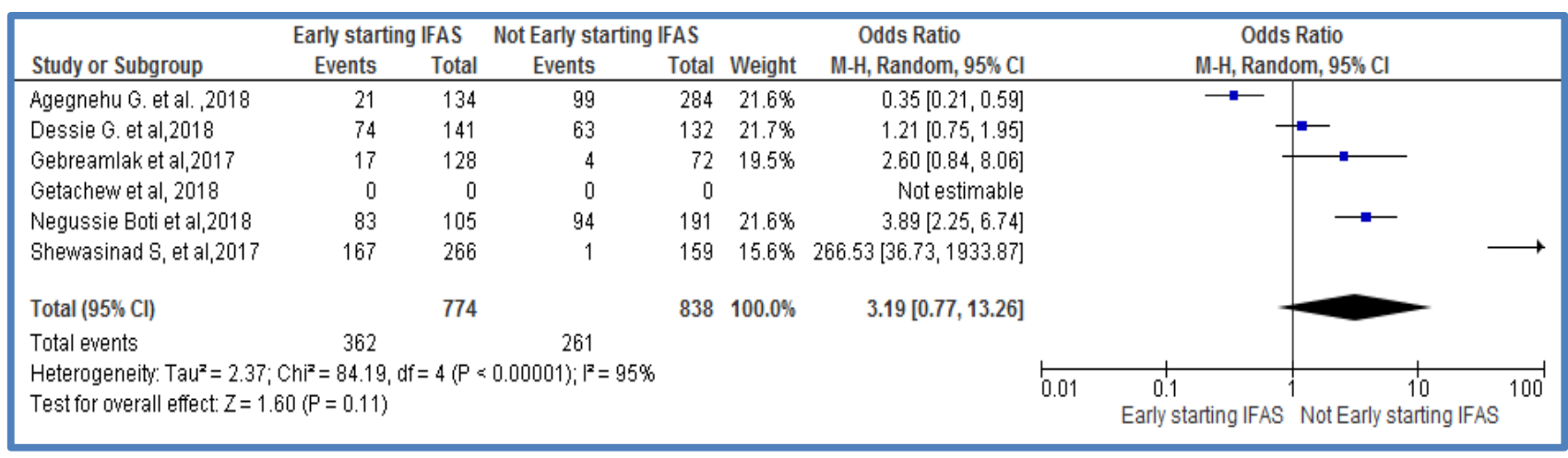

Figure 7: Forest plot displaying association of early timing antenatal care registration with compliance with IFAS among pregnant women in Ethiopia.

\section{Fourth visit for antenatal care (ANC)}

Association of lack of fourth visit for antenatal care and risk of developing noncompliance to IFAS during pregnancy was reported in seven studies. ${ }^{16,19,22,24,27,30}$ The result of meta-analysis showed that, pregnant women who had fourth visit for ANC during pregnancy were 1.58 times more likely to that, compliance with IFAS during pregnancy compared to those women who had no fourth visit for ANC, OR: 1.58, (95\% CI, 0.59,3.42). The heterogeneity test showed $\mathrm{I}^{2}=94 \%$ and statistical evidence of heterogeneity, $\mathrm{p} \leq 0.00001)$. Therefore, random-effect analysis was used.The Bag's and Egger's test for publication bias also showed, no statistical evidence of publication bias, $\mathrm{p}=0.930$ and $\mathrm{p}>0.0 .05$ respectively (Figure 6). 


\section{Early timing antenatal care registration}

Association of non-early timing of registration of antenatal care and risk of developing noncompliance to IFAS during pregnancy was reported in seven studies. ${ }^{14,18,22,23,28,31}$ The result of meta-analysis showed that, pregnant women who had early registered for antenatal care during pregnancy were 3.19 times more likely to have compliance with IFAS in relation to those women who had late registration for antenatal care, OR 3.19, (95\% CI, 0.77, 13.26). The heterogeneity test showed $\mathrm{I}^{2}=95 \%$ and statistical evidence of heterogeneity, $\mathrm{p} \leq 0.00001)$. Therefore, random-effect analysis was used. The Bag's and Egger's test for publication bias also showed, no statistical evidence of publication bias, $\mathrm{p}=0.2427$ and $\mathrm{p}=0.256$ respectively (Figure 7).

\section{DISCUSSION}

The current review was conducted to determine the prevalence and determinants of compliance with iron and folic-acid supplementation among pregnant women in Ethiopia. Eighteen studies and total of 6649 pregnant women were included for the review. The heterogeneity test shows statistical evidence of heterogeneity which was explained by variation of geographical location by region and types of study (community and facility based). The pooled meta-analysis of this review found that, the prevalence of compliance with IFAS was $46.1 \%$ in Ethiopia. Study conducted in Iran reported that, prevalence compliance of IFAS among pregnant women was $71.6 \%{ }^{32}$ Also in Egypt more than one-third of the pregnant women were not taking iron-folate tablets during pregnancy. ${ }^{33}$ Finding in India again revealed that,

compliance of IFAS among pregnant women was $64 \% .{ }^{34}$ In Mozambique the level of adherence with IFAS during pregnancy were $79 \% .{ }^{35}$ The pooled prevalence of compliance with IFAS among pregnant women in this study was lower than of studies conducted in Iran, India and Mozambique and comparable with study done in Egypt and Kenya.

The current pooled meta-analysis showed that, pregnant women who had knowledge of IFAS was almost three times more likely to have compliance with IFAS during pregnancy compared to those women who had no knowledge of IFAS and pregnant women who had knowledge of anaemia during pregnancy were more than five times more likely to have compliance of IFAS compared to those women who had no knowledge of Anaemia. Studies done in Egypt and Kenya revealed that, there was a high statistically significant positive correlation between women's core of knowledge about folic acid, iron and anaemia and their score of compliance to iron /folate supplementation during pregnancy. ${ }^{33,34}$

The pooled effect of current meta-analysis showed that pregnant women who had fourth visit for ANC during pregnancy were almost two times more likely to have compliance with IFAS during pregnancy compared to those women who had no fourth visit for ANC. Similarly an investigation conducted in five Asian countries (India, Indonesia, Nepal, Pakistan, and the Philippines) revealed that, pregnant women who had received at least three antenatal care visits were much more likely to adhere to at least 90 days of iron tablet or syrup or iron and folic acid tablets supplementation and also suggested antenatal care-seeking visits seem to be a particularly effective ways of reaching women and in increasing the likelihood of uptake of iron only or iron and folic acid supplements. ${ }^{36}$ An investigation in South Africa also suggested that, compliance was thought to be influenced by the regular good attendance of antenatal care clinic service. ${ }^{37}$

The result of meta-analysis showed pregnant women who had early registered for antenatal care during pregnancy was three times more likely to have compliance with IFAS in relation to those women who had late registered for antenatal care. Similarity study done in Malawi reported, attending antenatal care during the first trimester were significantly associated with increased odds of taking iron supplementation for 90 days or more during pregnancy. ${ }^{38}$

\section{Strength and limitation}

This review used extensive exploration method and more than one reviewer had taken part in all course of review process. PRISMA guideline was carefully tracked throughout review path. Nevertheless, this review has certain defects. Firstly, study lacks representativeness as, no data was found from some of regions in the countries such as Gambela and Benushangul Gumuz regions. Secondly, studies have been omitted due to poor statistics report, small sample size, inadequate data and qualitative studies. Finally, since only cross sectional studies were involved outcome variable may possibly be affected by confounding variable. Thus, this limitation might influence the overall prevalence of compliance among pregnant women in Ethiopia.

\section{CONCLUSION}

Current paper finding suggests that lack of compliance of IFAS in pregnancy is rampant (all most half) in Ethiopia. Factors comprise; lack of counselling on IFAS, lack of knowledge on IFAS and anaemia during pregnancy, lack of fourth visit antenatal care and non-early timing of antenatal care registration were statistically related with compliance of IFA supplementation. These call the careful appraisal of Government and non-Governmental organization focus on interventions to promote the strengthening of antenatal care, supplementation of IFAS and establishment counselling of pregnant women to adhere to IFA supplementation during their pregnancy and measures are required to escalate compliance with IFA Supplementation in pregnancy in Ethiopia. Probable suggestion for supplementation needs to make sure that 
women be given IFAS in pregnancy as WHO reference (minimum 90 tablets).

Funding: No funding sources

Conflict of interest: None declared

Ethical approval: Not required

\section{REFERENCES}

1. World Health Organization. Global prevalence of anemia in 2011. Available at: https://www.who.int/ nutrition/publications/micronutrients/global_prevalen ce_anaemia_2011/en/. Accessed on 10 August 2020.

2. World Health Organization. WHO global database on anaemia. Worldwide prevalence of anaemia 1993-2005. Available at: https://www.who.int/ nutrition/publications/micronutrients/anaemia_iron_d eficiency/9789241596657/en/. Accessed on 10 August 2020.

3. Fakher DM, Alhakam FAA, Fouad W. Maternal serum ferritin in relation to birth weight. Asian Acad Manag J. 2015;13:174-9.

4. Khambalia AZ, Collins CE, Roberts CL, Morris JM, Powell KL, Tasevski V, Nassar N. High maternal serum ferritin in early pregnancy and risk of spontaneous preterm birth. $\mathrm{Br} J$ Nutr. 2015;114(3):455-61.

5. Shen PJ, Gong B, Xu FY, Luo Y. Four trace elements in pregnant women and their relationships with adverse pregnancy outcomes. Eur Rev Med Pharmacol Sci. 2015;19(24):4690-7.

6. Haider BA, Olofin I, Wang M, Spiegelman D, Ezzati M, Fawzi WW, Nutrition Impact Model Study Group (aneamia). Anaemia, prenatal iron use, and risk of adverse pregnancy outcomes: systematic review and meta-analysis. BMJ. 2013;346:f3443.

7. Fowkes FJI, Moore KA, Opi DH, Simpson JA, Langham F, Stanisic DI, et al. Iron deficiency during pregnancy is associated with a reduced risk of adverse birth outcomes in a malaria-endemic area in a longitudinal cohort study. BMC Med. 2018;16:156.

8. Shag A, Yassin I, Elhardello O. Prevalence, types and determinants of anemia among pregnant women in Sudan: a systematic review and meta-analysis. BMC Hematol. 2018;18:31.

9. Rodriguez-Bernal CL, Rebagliato $\mathrm{M}$, Ballester. Maternal nutrition and fetal growth: the role of iron status and intake during pregnancy. Nutr Diet Suppl. 2012;4:25.

10. Gogoi M, Prusty RK. Maternal anaemia, pregnancy complications and birth outcome: evidences from North-East India. J North east India Stud. 2013;3(1):71-85.

11. Lozoff B, Jimenez E, Wolf AW. Long-term developmental outcome of infants with iron deficiency. N Engl J Med. 1991;325(10):687-94.

12. Tailor VP, Sengupta R. Impact of dietary pattern on nutritional status of pregnant women in low and high strata between the age group of 30-39 years in Mumbai. J Adv Med Med Res. 2019;29(8):1-9.
13. Milman N, Taylor CL, Merkel J, Brannon PM. Iron status in pregnant women and women of reproductive age in Europe. Am $\mathrm{J}$ Clin Nutr. 2017;106(Suppl 6):1655S-62S.

14. Arega Sadore A, Abebe Gebretsadik L, Aman Hussen M. Compliance with Iron-Folate Supplement and Associated Factors among Antenatal Care Attendant Mothers in Misha District, South Ethiopia: Community Based Cross-Sectional Study. J Environ Public Health. 2015;2015:781973.

15. Taye B, Abeje G, Mekonen A. Factors associated with compliance of prenatal iron folate supplementation among women in Mecha district, Western Amhara: a cross-sectional study. Pan Afr Med J. 2015;20:43.

16. Asmamaw D, Biftu G, Tadesse A, Haimanot A. Iron and folic acid supplementation adherence among pregnant women attending antenatal care in North Wollo Zone northern Ethiopia: institution based cross-sectional study. BMC Res Notes. 2019;12:107.

17. Gashaw A, Azeb A, Henok D, Baye D. Adherence to iron and folic acid supplement and associated factors among antenatal care attendant mothers in Lay Armachiho health centers, Northwest, Ethiopia. Int J Reprod Med.2019;2019:5863737.

18. Gebreamlak B, Dadi AF, Atnafu A. High Adherence to Iron/Folic Acid Supplementation during Pregnancy Time among Antenatal and Postnatal Care Attendant Mothers in Governmental Health Centers in Akaki Kality Sub City, Addis Ababa, Ethiopia: Hierarchical Negative Binomial Poisson Regression. PLoS One. 2017;12(1):e0169415.

19. Gebremariam AD, Tiruneh SA, Abate BA, Engidaw MT, Asnakew DT. Adherence to iron with folic acid supplementation and its associated factors among pregnant women attending antenatal care follow up at Debre Tabor General Hospital, Ethiopia, 2017. PLoS One. 2019;14(1):e0210086.

20. Gebremedhin S, Samuel A, Mamo G, Moges T, Assefa T. Coverage, compliance and factors associated with utilization of iron supplementation during pregnancy in eight rural districts of Ethiopia: a cross-sectional study. BMC Public Health. 2014; 14:607.

21. Gebremichael TG, Haftu H, Gereziher TA. Time to start and adherence to iron-folate supplement for pregnant women in antenatal care follow up; Northern Ethiopia. Patient Prefer Adherence. 2019;13:1057-63.

22. Getachew M, Abay M, Zelalem H. Magnitude and factors associated with adherence to Iron-folic acid supplementation among pregnant women in Eritrean refugee camps, northern Ethiopia. BMC Pregnancy Childb. 2018;18:83.

23. Gizew D. Drug use evaluation of iron with folic acid during pregnancy at Alem Ketema Enat Hospital, North shoa, Amhara, Ethiopia. J Health Med Nurs. 2018;48:25-36.

24. Ibrahim AA, Javed AQ, Abhay K, Shariff A, Sinaga M, Mali T. Socio-Economic factors influence iron- 
folic acid supplementation during pregnancy compliance with WHO guideline in eastern Ethiopia. Int J Creat Res Thoughts. 2018;6(1):570-5.

25. Birhanu J, Mekonen S. Non-Adherence to iron/folate supplementation and associated factors among pregnant women who attending antenatal care visit in selected public health institutions at Hosanna Town, Southern Ethiopia. J Nutr Disorders Ther. 2018; $8: 230$.

26. Zemenu YK, Tegibelu A, Alemneh KD, Zelalem T. Compliance with iron folic acid associated factors among pregnant women through pill count in Hawassa city, South Ethiopia: a community based cross-sectional study. Reprod Health. 2019;16:14.

27. Molla T, Guadu T, Muhammad EA, Hunegnaw MT. Factors associated with adherence to iron folate supplementation among pregnant women in West Dembia district, northwest Ethiopia: a cross sectional study. BMC Res Notes. 2019;12(1):6.

28. Boti N, Bekele $\mathrm{T}$, Godana W, Getahun E, Gebremeskel F, Tsegaye B, Oumer B. Adherence to Iron-Folate Supplementation and Associated Factors among Pastoralist's Pregnant Women in Burji Districts, Segen Area People's Zone, Southern Ethiopia: Community-Based Cross-Sectional Study. Int J Reprod Med. 2018;2018:2365362.

29. Wondwossen, Murugan R. Determinants of adherence to folic acid supplementation among pregnant women. Int J Ther Appl. 2018;35:197-203.

30. Missa T, Mamo W, Azeb A, Terefe D, Abere W. Antenatal care and mothers' education improved iron-folic acid adherence at Denbiya district health centers, Northwest Ethiopia: using pills count method. Arch Public Health. 2019;77:30.

31. Sisay S, Sophonias N. Adherence and associated factors of perinatal iron and supplementation among pregnant women in who attend antenatal care in health facility at Mizan-Aman town, bench Maji zone, Ethiopia. J pregnancy child. 2017;4:3.

32. Stang A. Critical evaluation of the Newcastle-Ottawa scale for the assessment of the quality of nonrandomized studies in meta-analyses. Eur $\mathbf{J}$ Epidemiol. 2010;25(9):603-5.

33. Siabani S, Siabani S, Siabani H, Moeini Arya M, Rezaei F, Babakhani M. Determinants of Compliance With Iron and Folate Supplementation Among Pregnant Women in West Iran: A Population
Based Cross-Sectional Study. J Family Reprod Health. 2018;12(4):197-203.

34. Ahamed NH, Kotb SAM, Hassanen RH. Knowledge of pregnant women regarding the factors affecting their compliance with iron and folate supplementation. J Nurs Health Sci. 2018;7(6):6680.

35. Sajith M, Nimbargi V, Shah S, Tekawade S, Agiwale J, Pawar A. Correlations of adherence to iron supplements and prevalence of anemia in antenatal women. Int J Reprod Contracept Obstet Gynecol. 2016;5(10):3448-52.

36. Nwaru BI, Salomé G, Abacassamo F, Augusto O, Cliff J, Sousa C, Regushevskaya E, Parkkali S, Hemminki E. Adherence in a pragmatic randomized controlled trial on prophylactic iron supplementation during pregnancy in Maputo, Mozambique. Public Health Nutr. 2015;18(6):1127-34.

37. Warvadekar K, Reddy JC, Sharma S, Dearden KA, Raut MK. Socio-demographic and economic determinants of adherence to iron intake among pregnant women in selected low and lower middle income countries in Asia: insights from a crosscountry analyses of global demographic and health surveys. Int $\mathbf{J}$ Community Med Public Health. 2018;5(4):1552-69.

38. Mbhenyane $\mathrm{X}$, Cherane $\mathrm{M}$. Compliance with the consumption of iron and folate supplements by pregnant women in Mafikeng local municipality, North West province, South Africa. Afr Health Sci. 2017;17(3):657-70.

39. Titilayo A, Palamuleni ME, Omisakin O. Sociodemographic factors influencing adherence to antenatal iron supplementation recommendations among pregnant women in Malawi: Analysis of data from the 2010 Malawi Demographic and Health Survey. Malawi Med J. 2016;28(1):1-5.

Cite this article as: Fite MB, Denio AD, Muyhe A, Merdassa E, Desalegn M, Gurmesa TT. Compliance with iron and folic acid supplementation and associated factors among pregnant women in Ethiopia: a systematic review and meta-analysis. Int $\mathbf{J}$ Sci Rep 2020;6(12):514-22. 